IZADP No. 4045

Unintended Effects of National-based Active Labour Market Policies

Carlo Altavilla

Floro Eresto Caroleo

February 2009 


\title{
Unintended Effects of National-based Active Labour Market Policies
}

\author{
Carlo Altavilla \\ University of Naples "Parthenope" \\ Floro Ernesto Caroleo \\ University of Naples "Parthenope" \\ and IZA
}

Discussion Paper No. 4045

February 2009

\author{
IZA \\ P.O. Box 7240 \\ 53072 Bonn \\ Germany \\ Phone: +49-228-3894-0 \\ Fax: +49-228-3894-180 \\ E-mail: iza@iza.org
}

\begin{abstract}
Any opinions expressed here are those of the author(s) and not those of IZA. Research published in this series may include views on policy, but the institute itself takes no institutional policy positions.

The Institute for the Study of Labor (IZA) in Bonn is a local and virtual international research center and a place of communication between science, politics and business. IZA is an independent nonprofit organization supported by Deutsche Post Foundation. The center is associated with the University of Bonn and offers a stimulating research environment through its international network, workshops and conferences, data service, project support, research visits and doctoral program. IZA engages in (i) original and internationally competitive research in all fields of labor economics, (ii) development of policy concepts, and (iii) dissemination of research results and concepts to the interested public.
\end{abstract}

IZA Discussion Papers often represent preliminary work and are circulated to encourage discussion. Citation of such a paper should account for its provisional character. A revised version may be available directly from the author. 
IZA Discussion Paper No. 4045

February 2009

\section{ABSTRACT \\ Unintended Effects of National-based Active Labour Market Policies}

Labour market policies settled at national level imply a "one-size-fits-all" labour market strategy. This strategy might not sufficiently take into account region-specific economic structures. In this paper we employ a panel factor-augmented vector autoregression (FAVAR) to evaluate whether active labour market programs (ALMPs) might asymmetrically affect labour markets at regional level. Given the significant difference between Italian regional economies we separately analyse two areas: the Centre-North and the South. Our results suggest that the timing and magnitude of the reaction of employment rate to ALMP shocks in the two areas is substantially different. Moreover, forecast error variance decomposition highlight that different variables seem to drive employment dynamics. In the South employment is mainly driven by its own shocks and by social and economic context variables. By contrast, in the northern regions, the employment dynamics is significantly explained by the dynamics of nominal and policy variables such as remunerations and ALMP.

JEL Classification: $\quad$ C33, J64

Keywords: $\quad$ Active Labour Market Policies, FAVAR

Corresponding author:

Carlo Altavilla

University of Naples "Parthenope"

Faculty of Economics

Department of Economic Studies

Via Medina, 40

I - 80133 Naples

Italy

E-mail: Altavilla@uniparthenope.it 


\section{Introduction}

This paper explores the role that active labour market programs (ALMP) settled at national level might have on regional labour market performance ${ }^{1}$.

Since the early 1990s, most OECD countries have progressively shift resources from passive income support, like unemployment benefits, to pro-active measures. In Europe, this trend has been significantly influenced by the establishment of the European Employment Strategy (EES). In fact, the EES has stressed the importance of the interaction between active and passive policies in influencing labour market outcomes $^{2}$.

However, when analysing the amount of resources each country assigns to ALMP a very heterogeneous picture emerges. As shown in Figure 1, only few countries spend - excluding public employment services expenditures- a percentage over 1\% of GDP in ALMP. This percentage is, on average, lower than the ratio of spending on passive policies to GDP.

In Italy, expenditure in ALMP as a percentage of GDP has been decreasing during the last decades getting down to $0.5 \%$. As shown in Figure 1, this percentage is lower than the one observed for the majority of European countries.

Figure 1: Public Expenditure on ALMP a percentage of GDP (2005-2006)

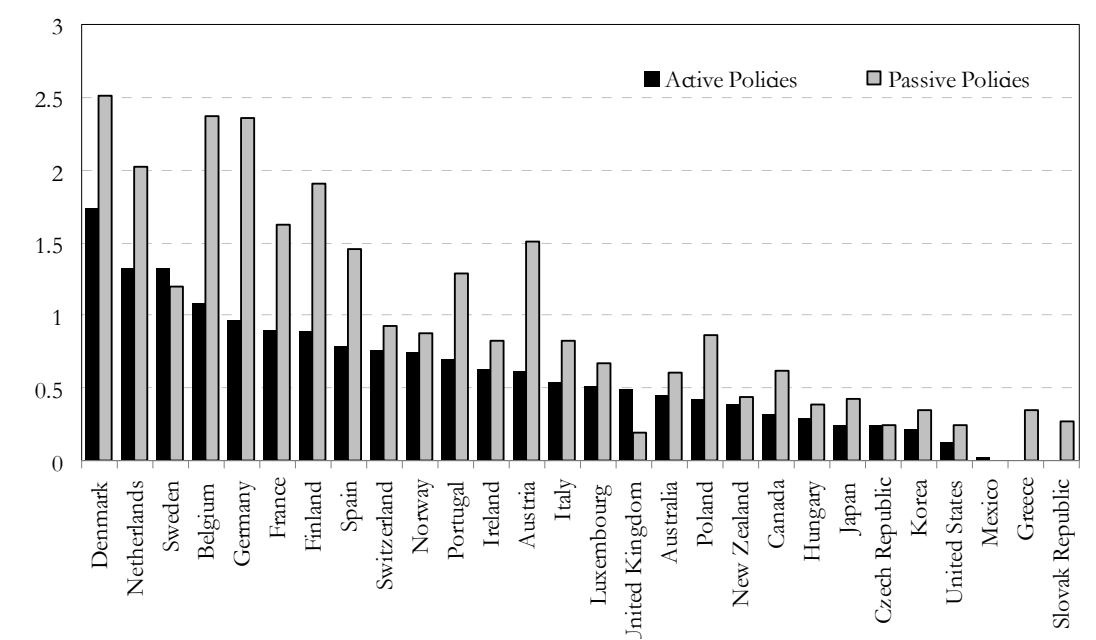

Source: $O E C D$

\footnotetext{
${ }^{1}$ See Nickell and Layard (1997), Calmfors (1994), Altavilla and Caroleo (2006b).

2 See chapter 3 on "Effective European Active Labour Market Policies" in the 2006 report on "Employment in Europe" for a detailed overview of the existing knowledge on ALMP in Europe.
} 
At the same time, as depicted in Figure 2, Italian labour market authorities have changed the composition of expenditure in labour market policies by substantially decreasing region-specific programs. This reduction signals the low interest of policymakers in managing regional-oriented policies at national level ${ }^{3}$. Indeed, this strategy follows the main lines of the EES.

Figure 2: Labour Market Policy in Italy

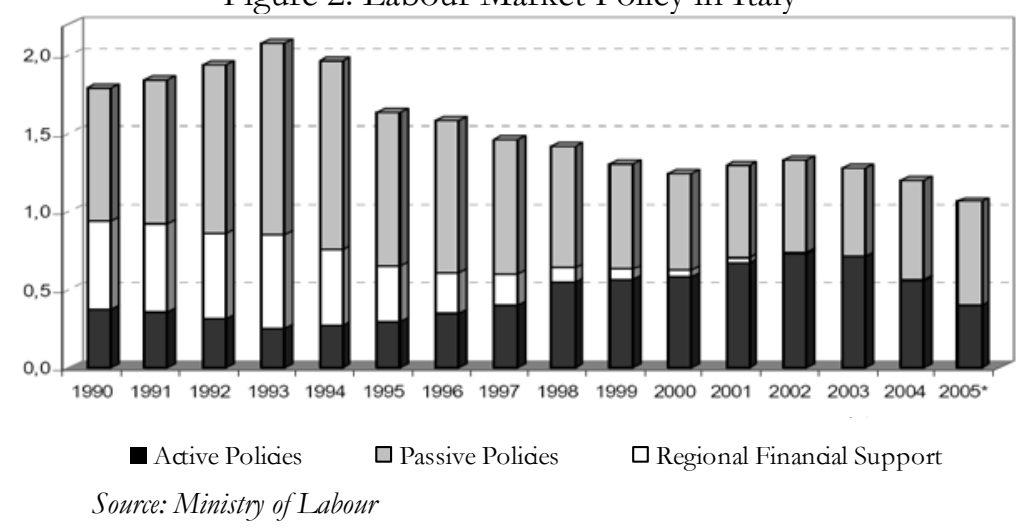

However, the Italian labour market is still characterised by considerable regional differences. The well-known dualistic structure of the Italian economy largely reflects substantial differences in labour market indicators ${ }^{4}$.

Figure 3 summarizes the evolution of regional disparities as measured by a simple standardised variation index ${ }^{5}$ over the period 1995-2007, for the 124 variables used in the empirical analysis. This figure synthesizes the data reported in column VI of the table presented in Appendix 1. Each number on the horizontal axis is associated to a particular variable, as in Table A.1. A value greater than zero means that, on average, during the covered period there has been an increase in regional disparities.

As for most variables the average of the variation index is positive, we can conclude that, over the period considered in the analysis, the volatility of the economic variables among regions has substantially increased.

Given the high level of regional disparities observed in Figure 3, we can infer that labour programs settled at national level might have heterogeneous and unintended effects on regional economies.

\footnotetext{
3 This policy orientation can be retrieved from several documents of the Italian Ministry of Labour such as Ministero del Lavoro (2006, 2007).

4 See Caroleo and Destefanis (2006).

${ }^{5}$ For each year, the variation index is calculated as the ratio between the standard deviation and the mean of a given variable.
} 
Starting from these considerations, the aim of this paper is to empirically evaluate whether the "one-size-fits-all" labour market strategy adopted by Italian policymakers during the last decade might generate asymmetries in the effect of ALMP on regional labour market performance. Using a panel-factor augmented-vector autoregression (FAVAR) we estimate whether ALMP might heterogeneously affect labour market variables at a regional level.

Figure 3: Variation Index for Regional disparities
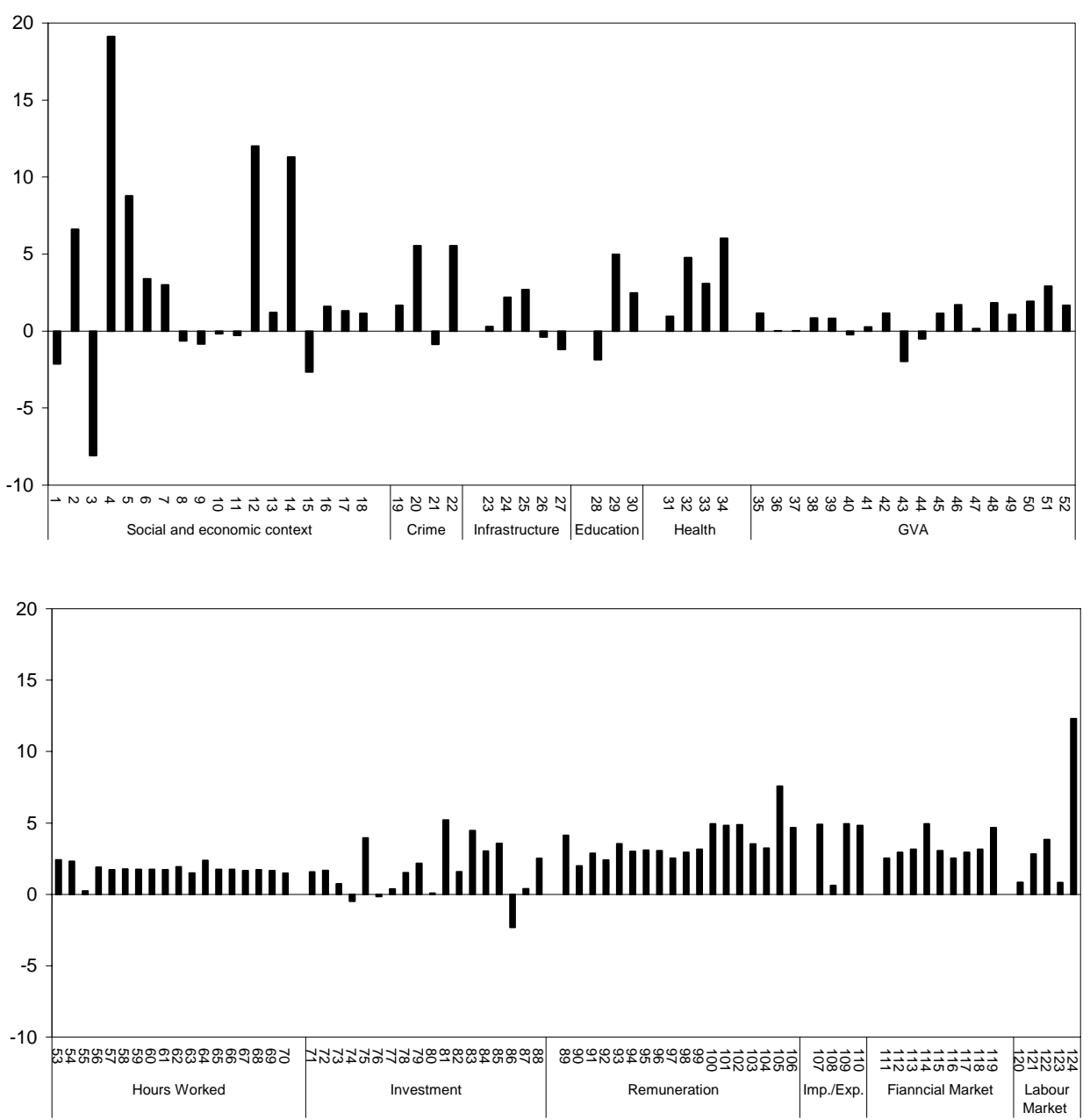

Note: The chart report the standardised variation index for the 124 variables used in the empirical analysis.

Variables on the $\mathrm{x}$-axes are organized according to the order given in table A1.

The remainder of the paper proceeds as follows. Section 2 describes the theoretical framework and reviews the literature on programme evaluations. Section 3 reports the 
empirical findings and discusses the effects of an ALMP shock on labour market variables. Section 5 summarizes the paper's main findings and concludes.

\section{Theoretical background}

The hypothesis underlying our empirical investigation is that, given the dualistic economic structure characterizing the Italian regions, the ALMP might produce asymmetric effects on regional labour markets. More specifically, ALMP may asymmetrically influence the matching process as well as the labour market equilibrium conditions at a regional level ${ }^{6}$.

From a theoretical point of view the effects of ALMP can be analysed by evaluating their impact on the equilibrium relationship between unemployment and vacancies within a model of job matching, i.e. the Beveridge Curve framework. This curve represents a negative relationship between unemployed workers and job vacancies, i.e. the number of unfilled jobs. More precisely, the Beveridge $\mathrm{Curve}^{7}$ can be viewed as the result of a process in which workers and firms engage in costly search, because of informational or locational imperfections, to find each other. The key argument is that the "matching function" (see Petrongolo and Pissarides, 2001) describes the ways the match between unemployed workers and unfilled jobs takes place; the behaviour of workers in searching for a job; the behaviour of employers in screening applicants for a vacancy; and, the probability that the job contact takes place.

The determinants of the matching function influence the position and the slope of the Beveridge Curve. The slopes depends on the search intensity of job seekers and on labour market mismatches, while the job finding rate, and therefore the equilibrium condition, depends also on the decision of a job seeker to accept a job and on the employer acceptance decision.

\footnotetext{
${ }^{6}$ See Altavilla and Caroleo (2006b).

7 The theoretical foundations of the Beveridge Curve are substantially twofold: the first, starting from the Hansen model (Dow and Dicks-Mireaux, 1958; Lipsey, 1960; Holt and David, 1966; Hansen, 1970; and Bowden, 1980), derives the matching function from an aggregation over distinct markets in the presence of frictions and of limited mobility of labour. More recently an alternative approach was developed which arises from a matching function combined with job search (Mortensen and Pissarides, 1994; Petrongolo and Pissarides, 2001).
} 
Movements in the Beveridge curve may be partly explained by changes in the cross-region dispersion of employment growth. In fact, if labour demand is growing in some parts of the country while shrinking in others, a regional mismatch may take place. As a consequence, in order for the unemployed to be matched with available vacancies, they should move across regions. This costly and time-consuming reallocation mechanism delays the job-matching process and rise the probability of high levels of both unemployment and vacancies.

However, the position and slope of the Beveridge Curve is also significantly affected by active labour policies (e.g. Jackman et al. 1990). More active than passive labour policies cause the Beveridge Curve to shift inward since they reduce labour market mismatches and search frictions. Nevertheless, the final effect of ALMP on regional labour market tightness could be heterogeneous and uncertain. The empirical literature on macroeconomic evaluation of ALMP stresses that, when taking into account not only the direct effects on participants but also the indirect effects on nonparticipants, unintended negative effects (like displacement, deadweight and substitution effects) may worsen the labour market outcomes ${ }^{8}$.

During the last decade, several studies have doubt the effectiveness of ALMP. Precisely, microeconometric evaluations suggest significant differences in the impact of these programs for different groups of workers. Heckman et al. (1999), Calmfors et al. (2001), Martin and Grubb (2001), for example, found that because of indirect effects some programs might eventually worsen unemployment conditions.

More recently, there has been a growing interest in the analysis of the macroeconomic effect of specific programmes of active labour policies using regional data (Hujer et al., 2007; Hujer and Zeiss, 2003; Hujer et al., 2002; Hagen, 2003; Fertig et al., 2006; Puhani, 2003). Most of these studies estimate an augmented Beveridge Curve and show mixed results regarding the effects of ALMP on labour market performance. However, only few studies have analysed the possible unintended effect of labour policies at regional level resulting from heterogeneous economic characteristics.

8 See Altavilla and Caroleo (2006a,b). For a review of the debate on the evaluation of the effects of ALMP on labour market see: Kluve et al. (2006); Kluve (2006); Calmfors, Forslund and Hemstròm (2001); Hujer and Caliendo (2000), Mourre (2006), Caliendo et al. (2008), Büttner and Prey (1998), Marè (2004). 
Following a seminal paper of Warren (1991), several authors such as Fahr and Sunde (2006), Ilmakunnas and Pesola (2003) and Ibourk et al. (2004) apply a stochastic production frontier approach to model the matching process at regional level. Destefanis and Fonseca (2007) adopt a similar approach in order to evaluate the impact of a labour market reform in Italy (the so-called Treu Reform of 1996) on the unemployment-vacancy relationship across regions. They find the existence of a substantial difference in the matching efficiency between the southern and the northern regions.

The present paper investigates to what extent regional labour markets in Italy might be influenced by unintended effects of labour policies measures that ignore differences in the regional economic structures. To this end, the next section presents a macroeconomic evaluation of ALMP in Italian regions.

\section{The Macroeconometric Framework}

This section focuses on possible asymmetric effects that national ALMP might have on regional labour markets. The hypothesis underlying our empirical investigation is that, given the different economic structures characterizing the Italian regions, ALMP might produce asymmetric effects on the performance of regional labour markets.

We use a panel dataset of Italian regions, covering the period 1996:1-2007:4. The data are quarterly and are collected from ISTAT, SVIMEZ, Bank of Italy and CambridgeReg and the Ministry of Labour9. Figure 4 depicts the relationship between the employment rate and ALMP participants over the period 1996:1-2007:4.

A visual inspection seems to suggest that for most regions lower employment rates are associated with lower number of participants in ALMP. Indeed, the positive slope of the linear regression line (the solid line in the graph) indicates that regions where the participation in active policies is higher, like in Piedmond, Trentino-Alto Adige; and Friuli-Venezia-Giulia, present higher employment rates.

\footnotetext{
9 See Appendix 1 for a detailed description of the variables used in the analysis and their sources. Appendix 2 describes the active labour market policies considered in the paper.
} 
Figure 4: Employment Rate and ALMP participants (1996-2007)

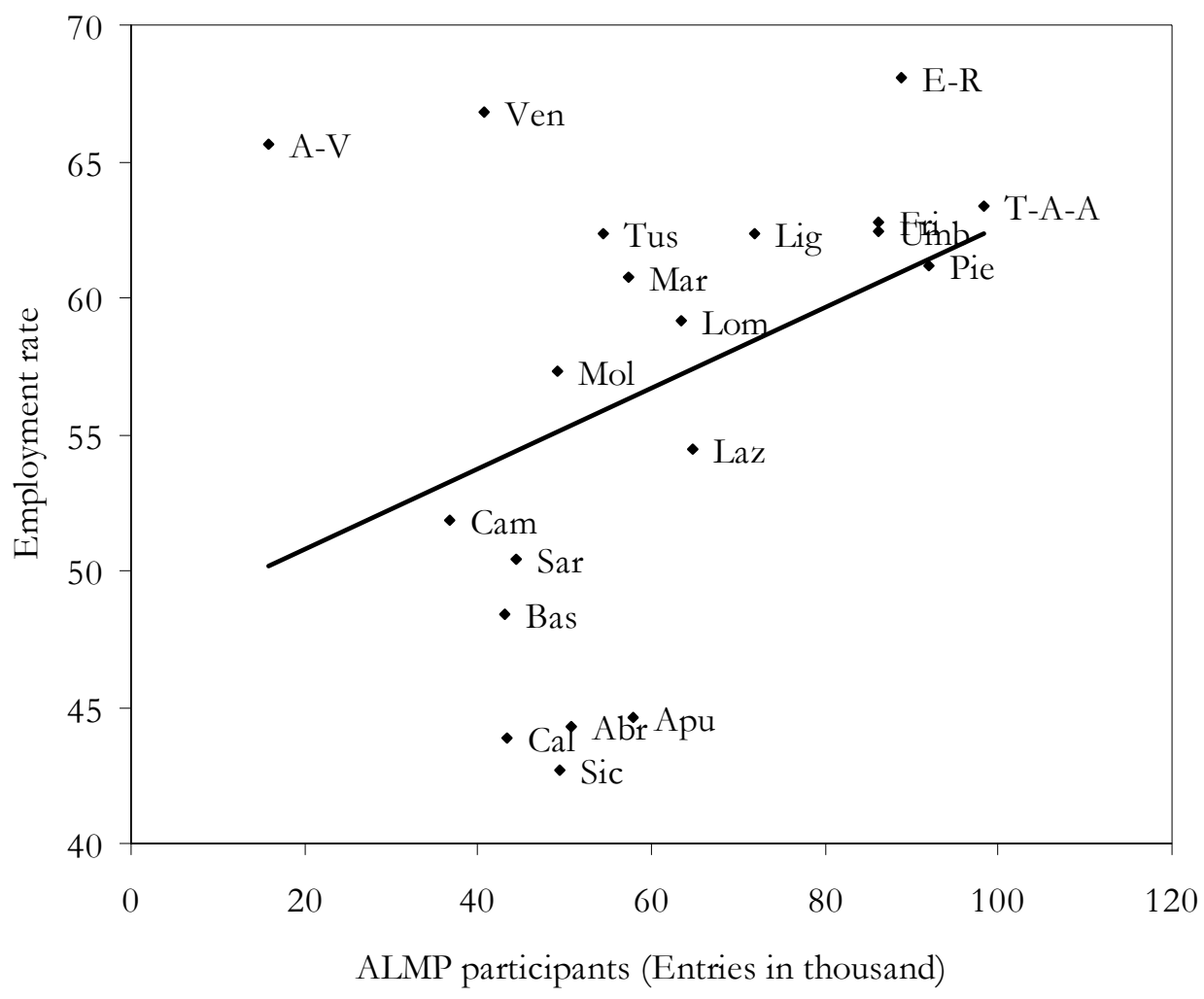

Note: Pie $=$ Piedmont; A-V = Aost Valley; Lom = Lombardia; T-A-A = Trentino-Alto Adige; Ven = Veneto; Fri = Friuli-Venezia-Giulia; Lig = Liguria; E-R = Emilia Romagna; Tus = Tuscany; $\mathrm{Umb}=$ Umbria; Mar = Marche = Lazio; Abr = Abruzzi; Mol = Molise; Cam = Campania $; \mathrm{Apu}=$ Apulia; $\mathrm{Bas}=$ Basilicata $; \mathrm{Cal}=$ Calabria $; \mathrm{Sic}=$ Siciy; $\mathrm{Sar}=$ Sardinia. The solid line represents the linear regression line.

\subsection{A panel FAVAR Model}

The econometric model we use to evaluate the effect of ALMP on labour market performance is a panel factor-augmented vector autoregressive model (FAVAR). Given the significant difference between Italian regional economies we separately analyse two areas. Precisely, we consider eight regions ${ }^{10}$ for Southern Italy, and twelve $^{11}$ for Centre-Northern Italy and specify two different models accordingly. These two models share the same set of explanatory variables and are estimated over the same sample period.

${ }^{10}$ Southern regions are Campania, Abruzzo, Molise, Apulia, Basilicata, Calabria, Sicily, Sardinia.

11 The twelve regions are Piedmont, Aosta Valley, Liguria, Lombardy, Trentino-Alto-Adige, Veneto, Friuli-Venezia-Giulia, Emilia Romagna, Marche, Tuscany, Umbria, and Lazio. 
We assume that $k$ economic variables form a vector $Y$ which describes the labour market policy transmission channel. More precisely, we assume that the vector $Y_{i t}(i=1, \ldots n$ and $t=1, \ldots ., T$ with $n$ indicates the number of regions considered in the model and $T$ the sample period considered in the analysis) contains the employment rate $\left(E_{i t}\right)$, the participation rate $\left(\right.$ Part $\left._{i t}\right)$, and the ratio between the number of participants in ALMP and the working-age population $\left(A L M P_{i t}\right)$. Following the standard approach, we could estimate the relationship among these variables by specifying a multivariate time series model such as a VAR. However, by analysing the dynamics governing the variables contained in $Y_{i t}$ we might not fully capture all relevant information. More specifically, in our case, we consider 120 additional timeseries $^{12}$ for each region, collected in a vector $X_{i t}$. These series are initially transformed to induce stationarity. Assuming that all additional information depends on $m$ unobservable factors summarized in the vector $F$ we can specify a FAVAR model that summarizes the joint evolution of $Y_{i t}$ and $F_{i t}$ :

$$
\left[\begin{array}{l}
F_{i t} \\
Y_{i t}
\end{array}\right]=A(L)\left[\begin{array}{l}
F_{i t-1} \\
Y_{i t-1}
\end{array}\right]+\varepsilon_{i t}
$$

Where $A(L)=I-A_{1} L-\ldots .-A_{p} L^{p}$ is a lag polynomial matrix of order $p$. For each region, the $(m+k) \times 1$ vector of error terms $\varepsilon_{i t}$ is mean 0 with covariance matrix $V$.

The above model cannot be directly estimated because of the non-observable factors. For each region, we assume that there exist some unobservable fundamental forces that affect the dynamics of the time-series belong to the vector $X_{i t}$ that can be summarized by $\boldsymbol{m}$ factors in the following observation equation:

$$
X_{i t}=\Lambda F_{i t}+e_{i t}
$$

\footnotetext{
12 All variables considered in the factor analysis and their transformations are reported in Appendix 1. When computing the common factors we do not consider the last two variables, the employment and participation rate, which are included in $Y_{i t}$.
} 
Where $\Lambda$ represent the $(m \times k) \times n$ matrices of factor loadings; while $e_{i t}$ is a mean-zero error vector representing the idiosyncratic component of $X_{i t}$. Equation (2) is the factor representation of the data.

The model, then, consists of a transition equation (1) and an observation equation (2) similar to the one proposed in Bernanke et al. (2005) and can be estimated by employing the two-step principal components procedure suggested in Stock and Watson $(1998,2002)$.

The first step consists of estimating $\boldsymbol{m}$ unobservable factors $\widehat{F}_{i t}$ as the principal components $^{13}$ of all macroeconomic time series $X_{i t}$. Following Bernanke et al. (2005), in order to identify the factors against any rotations we impose the following factor restriction ${ }^{14}: \widehat{F}_{i t}=\sqrt{T} \widehat{Z}$, where $\widehat{Z}$ correspond to the eigenvectors of the $m$ largest eigenvalues of $X X^{\prime}$.

In the second step, the FAVAR model described in equation (1), is estimated by standard methods, with $F_{i t}$ replaced by $\widehat{F}_{i t}$ and additional identifying assumption imposed. More precisely, model (1) is a reduced form VAR model, which contains a block recursive restriction that the unobservable factors do not respond to the ALMP shocks contemporaneously. A Choleski decomposition of the reduced form covariance matrix $V$ is used to orthogonalize the reduced form innovations and to identify the structural model. We order ALMP last and treat its innovations as labour policy "shocks". This ordering imposes the identifying assumption that employment and participation rate do not respond to labour policy innovations within the quarter.

In principle, once we have recovered $\widehat{F}_{i t}$, the panel FAVAR model can be estimated either under the null of homogeneity, using a fixed effects estimator, or under the alternative of heterogeneity of slope coefficients, i.e. using the mean group estimator of Pesaran and Smith (1995).

${ }^{13}$ The principal components are orthogonal linear combinations of the data that explain the maximal variances of the data contained in $X_{i t}$.

${ }^{14}$ In fact, given the rotational indeterminacy problem, unless identification assumptions are imposed on the factor loadings, it will always be possible to find some rotation of the factors which explains the same amount of total variation in the data but implies a different set of factor loadings. 
The mean group estimator allows coefficients and error variances to vary across regions and estimates (1) separately for each region. Pooled (or fixed effects) estimator by contrast, assumes that coefficients and error variances are homogeneous across regions, allowing only for region specific fixed effects.

As discussed in Pesaran and Smith (1995), results are likely to vary significantly with respect to the estimation method, i.e from the least restrictive, but potentially not efficient, mean group estimator, to the fixed effect estimator that only allows intercepts to vary across regions. We estimated the models with both techniques and compute a Haussman type test of the difference between the two estimators. Under the null of homogeneity the test statistic is distributed as a $\chi^{2}$ with $k+1$ degrees of freedom where $k$ stands for the number of explanatory variables. Applying this test, we can not reject the null of homogeneity in all estimated models. Specifically, we do not reject homogeneity in the model for South (the statistics equals to 3.17 with pvalue 0.17 ) as well as for the North (the statistics equals 1.21 with p-value 0.75 ). We then estimate all models by assuming slope homogeneity.

\subsection{Empirical Results}

This section presents the results of the two-step estimation procedure. We first concentrate on the principal component analysis and then on the simulation of the FAVAR model.

Figure 5 shows the outcome of the principal component analysis by way of a scree plot, which graphs the largest twenty eigenvalues of the data matrix. There appears to be a natural break at the fourth value, with the remaining eigenvalues flattening out. As shown in Table 1 the first four principal components explain on average $32 \%$, $12 \%, 7 \%$ and $6 \%$ of the total variance in our economic series, making a cumulative proportion of $58 \%$. Given the number of the time series included in the analysis, we consider this proportion sufficiently high. By contrast, the fifth and sixth components account for only $3 \%$ and $2 \%$ respectively. We also employ the Bai and $\mathrm{Ng}$ (2002) procedure for determining the number of static factors and find that PC1 and IC1 criteria substantially support our choice. 
Figure 5: Scree plot of eigenvalues from principal component analysis

South

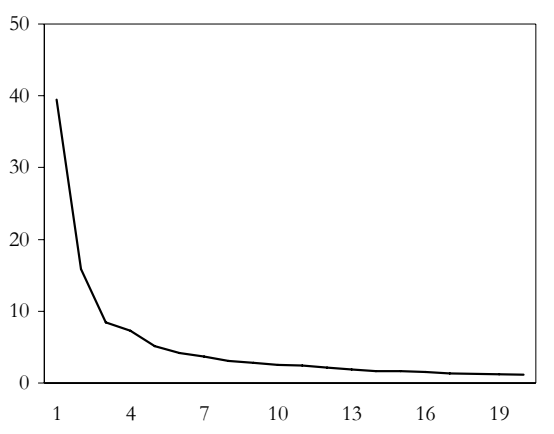

North

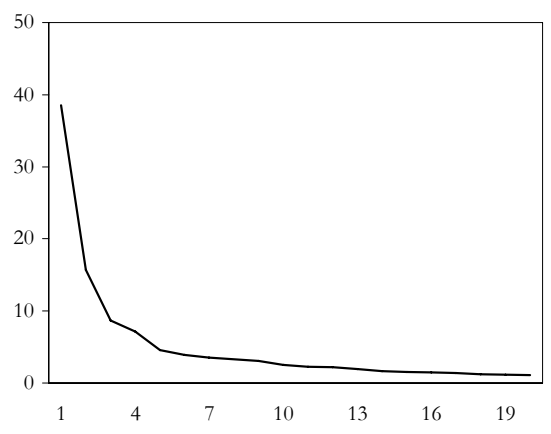

Table 1: Principal Components Analysis

\begin{tabular}{lcccc}
\hline & 1st PC & 2nd PC & 3th PC & 4th PC \\
\hline \hline South & & & & \\
Eigenvalue & 39.45 & 15.85 & 8.49 & 7.29 \\
Variance Explained (\%) & $32.33 \%$ & $12.99 \%$ & $6.96 \%$ & $5.98 \%$ \\
Cumulative Var. Exp. (\%) & $32.33 \%$ & $45.32 \%$ & $52.28 \%$ & $58.25 \%$ \\
& & & & \\
North & & & & \\
Eigenvalue & 38.52 & 15.71 & 8.65 & 7.16 \\
Variance Explained (\%) & $31.57 \%$ & $12.88 \%$ & $7.09 \%$ & $5.87 \%$ \\
Cumulative Var. Exp. (\%) & $31.57 \%$ & $44.45 \%$ & $51.54 \%$ & $57.40 \%$ \\
\hline
\end{tabular}

Figure 6 shows the percent of variance in a given variable explained by all the factors, i.e. the communality ${ }^{15}$. Communality for a variable is the sum of squared factor loadings for that variable (row), and thus is the percent of variance in a given variable explained by all the factors.

The figure suggests that for both areas of the country the four extracted factors explain a high percentage of the variance of the variables summarizing the social and economic structure (variables 1 to 18), investment (variables 71 to 88), financial market (variables 111 to 119 ) and labour market (variables 120 to 124). The variance of other variables, mostly the ones related to crime and infrastructure is less explained by the factors which are extracted, resulting in coefficients lower than 0.5 .

\footnotetext{
${ }^{15}$ In complete principal components analysis, with no factors dropped, communality is equal to 1.0 , or $100 \%$ of the variance of the given variable. As our model does not extract all the variance, the proportion of variance of a particular variable that is due to common factors is called communality. The proportion of variance that is unique to each variable is then the respective variable's total variance minus the communality.
} 
Figure 6: Extracted Communalities
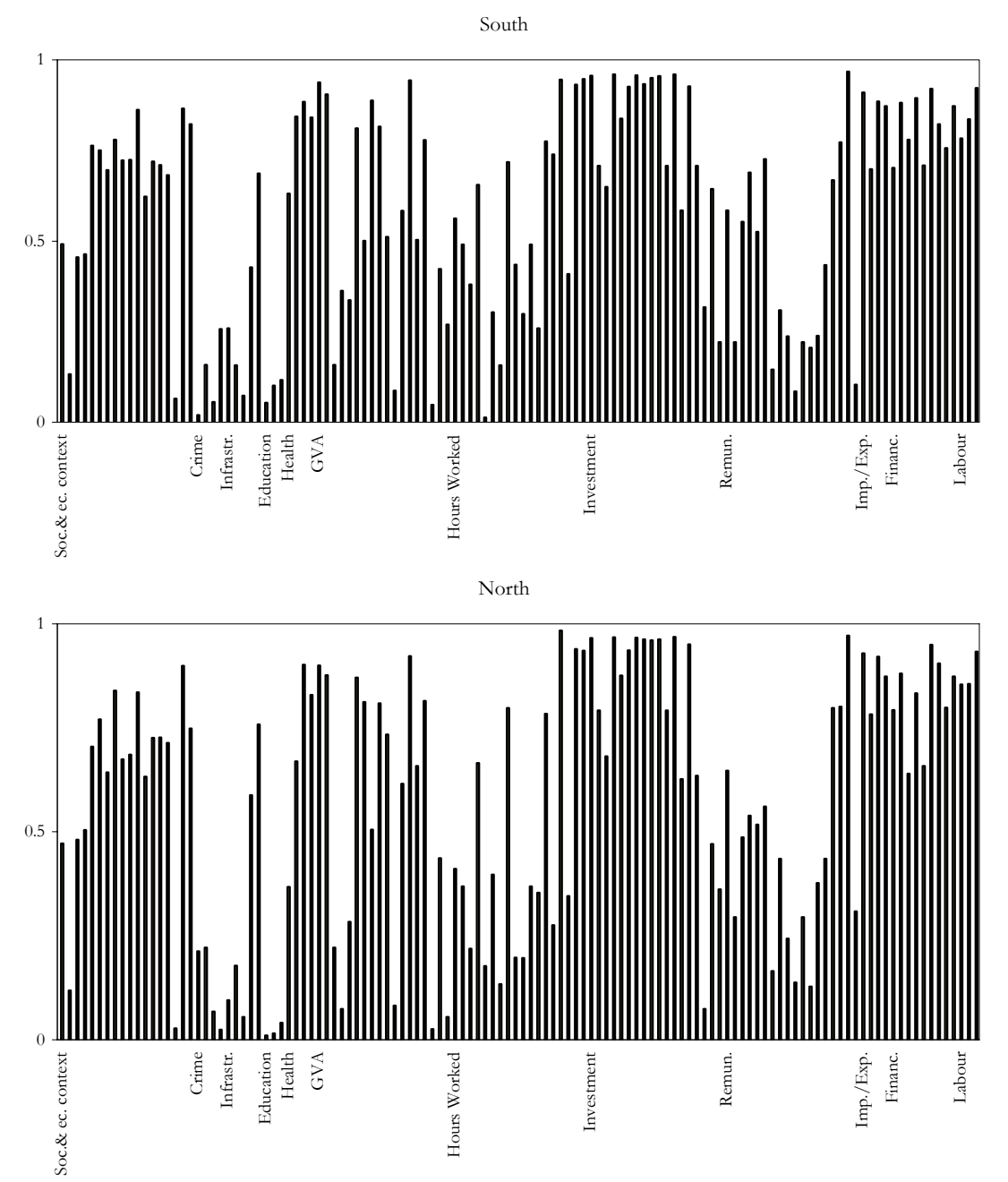

To explore what kind of interpretations could be assigned to the first four principal components, we employ an orthogonal rotation of the estimated eigenvectors using the varimax method. Varimax rotation seeks to maximize the variances of the squared normalized factor loadings across variables for each factor. This is equivalent to maximizing the variances in the columns of the matrix of the squared normalized factor loadings.

Figure 7 depicts the rotated components. The numbers on the horizontal axis refer to the ordering of the series as reported in Appendix 1 and the principal component 'loadings' are shown on the vertical axis. 
Figure 7: Loadings on selected principal components South
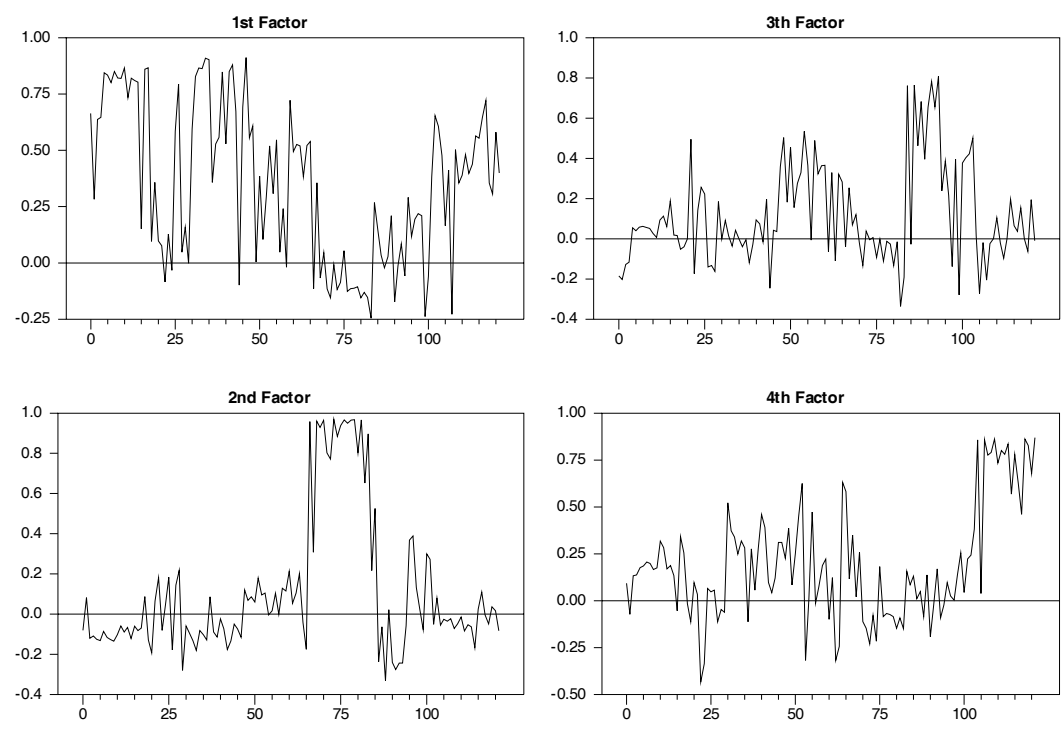

North
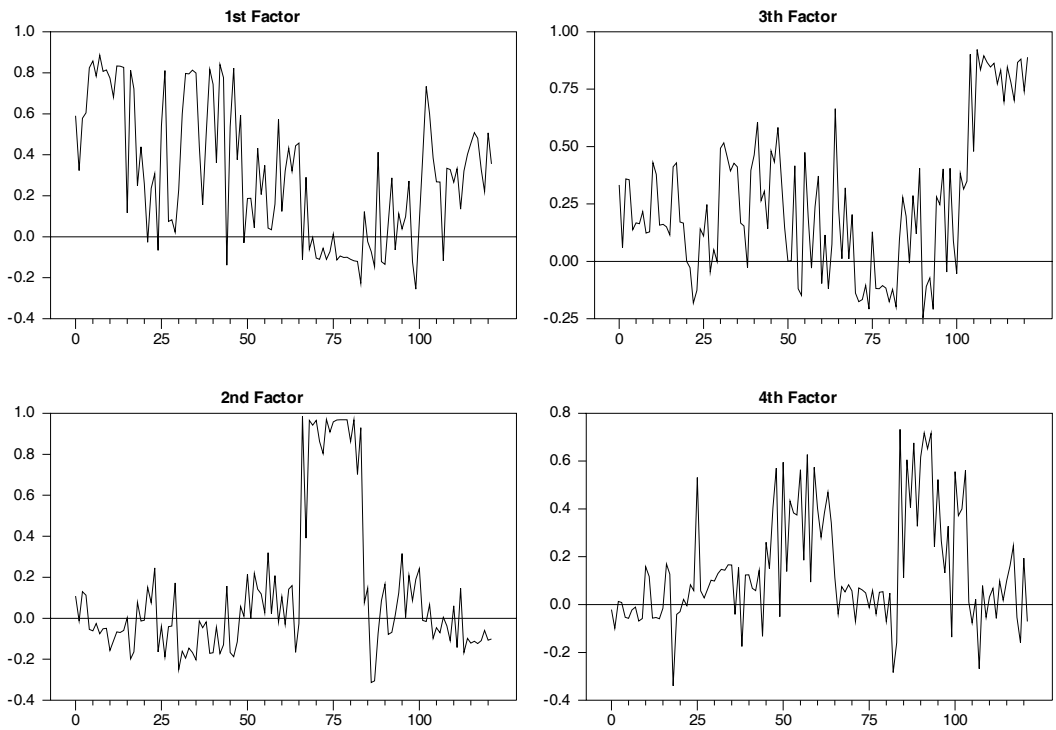

Note: Numbers on horizontal axis refer to the ordering of the variables as reported in Appendix 1. Then, 1-18 social and economic context; 19-22 crime; $23-27$ infrastructure; $28-30$ education; 31-34 health; 35-51 GVA; 53-70 hours worked; 71-88 investment; 89-106 remuneration; 107-110 import/export; 111-119 financial market; 120-124 labour market 
The first rotated principal component is a linear combination that places heavy weights on regional economic series related to social and economic context in both estimated models. The second rotated eigenvector clearly picks out the indicators associated with investment and hours worked for both south and north.

Interestingly, the third and fourth principal components for the south are very similar to the fourth and third components for the north. More precisely, the third component for the South and the fourth component for the North seem to be linked with remuneration. On the contrary, labour market variables and financial market indicators load highly on the third component for the North and the fourth component for the South.

We can now describe how these factors could be used in a standard VAR for evaluating the effect of ALMP on labour market performance. In fact, once we have estimated the FAVAR we can compute the dynamic effects of ALMP shocks on labour market variables examining in particular the similarity of employment responses in each area. This is accomplished by using impulse response functions with a structural decomposition of the variance covariance matrix explained above. A 32quarter horizon is considered.

The estimated responses to a $1 \%$ increase in $A L M P$ are reported in Figure 8. Each response is provided with the associated asymptotic confidence bands.

Impulse responses look reasonably well behaved and give rise to the usual humpshaped dynamics. The figure shows that all response functions are statistically significant. Moreover, the impulse responses for the northern regions are substantially larger than those for the southern ones. Most importantly, the results suggest that the employment rate in the selected regions responds to identical labour policy shocks with different speeds and movements, as well as with different magnitudes of the effects.

Table 2 outlines some key characteristics of the estimated response functions. In particular, it gives information about the maximum impact and the average responses of the employment and participation rate to $A L M P$ structural shocks. The table also considers the time that a shock takes to exert its maximum effect on employment and its cumulative effect.

Despite some qualitative similarities, the table seems to suggest the existence of different responses across regions. In both areas, an ALMP shock produces an 
increase in the employment rate. However, the magnitudes of the effect are quite dissimilar. Whilst in the South the employment rate increases by more than 20 basis points, an ALMP shock in the North rises the employment rate by 38 basis points.

The time-profile of the response functions is also significantly different. After an initial delay, the response function displays a hump-shaped pattern that reaches the maximum increase after roughly two years in the North and one year in the South. Asymmetries are also detected in the response of the participation rate. Again, the largest responses are observed in the North: in particular, the response of participation in the northern regions reaches a maximum of twenty-six basis points after 8 quarters, while the reaction of the southern Italian regions is smaller and more rapid: thirteen basis points after 4 quarters.

The different adjustment speeds of the employment rates to ALMP shocks for the two selected areas can be partly explained by the existence of a higher degree of labour market rigidity in the South. This finding suggests that the 'efficiency' of the labour market should be improved.

Figure 8: Responses of employment and participation rate to a 1\% increase in ALMP
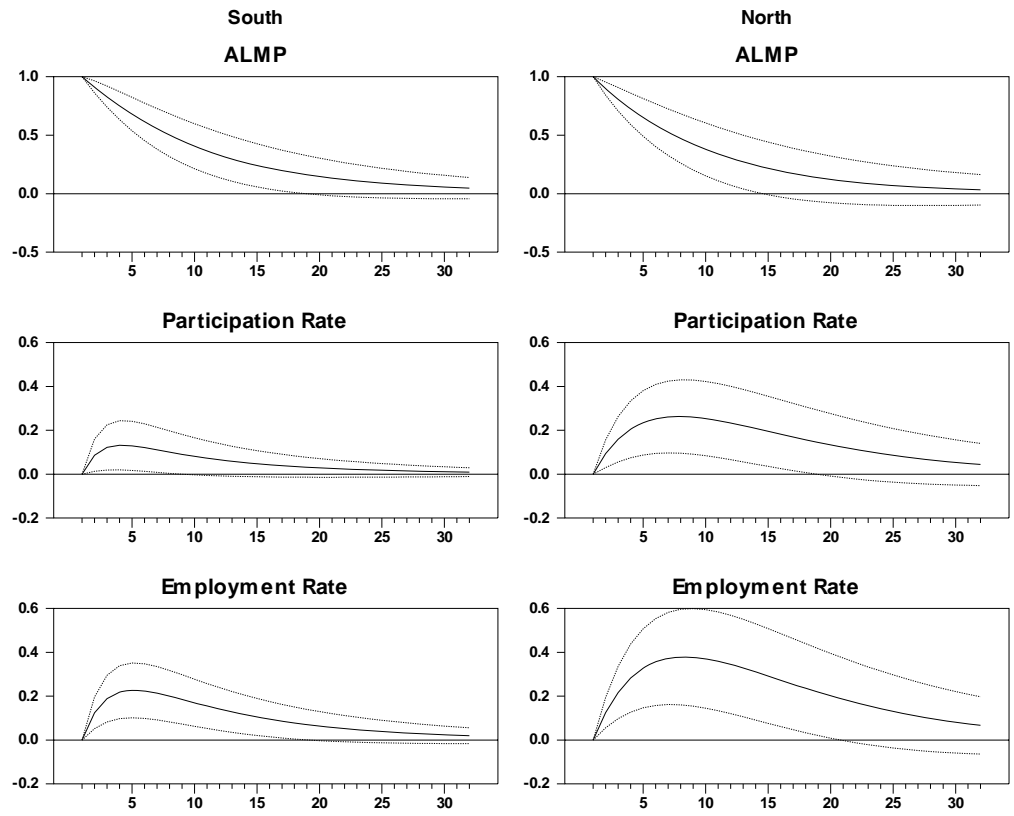
Table 2: Estimated Response Function Features

\begin{tabular}{lcccc}
\hline & \multicolumn{2}{c}{ South } & \multicolumn{2}{c}{ North } \\
\hline \hline & Part & $E$ & Part & $E$ \\
Average Effect & 0.051 & 0.100 & 0.150 & 0.220 \\
Cumulative Effect & 1.641 & 3.216 & 4.809 & 7.049 \\
Maximum Effect & 0.132 & 0.227 & 0.263 & 0.378 \\
Time to maximum & 4 & 4 & 8 & 8 \\
\hline
\end{tabular}

On the other hand, the different magnitudes of the effect can be explained by considering the existing differences in both the number of vacancies and the number of unemployed in the two areas. Whilst the northern regions are characterized by a large number of vacancies and a small number of unemployed workers (the upper-left part of the Beveridge curve), southern regions have a small number of vacancies and a large number of unemployed (the lower part of the Beveridge curve). It follows that an identical increase in ALMP has a greater effect on the northern employment rate.

Table 3 reports the responses of eleven selected variables to a $1 \%$ increase in ALMP at relevant horizons. The sign of the responses is largely in line with our a priori predictions. An increase in ALMP tends to reduce both the unemployment rate and the long-term unemployment. Moreover, GDP and investments positively react to the ALMP shock, in both areas.

Table 3: Response of selected Variables to a $1 \%$ shock in ALMP

\begin{tabular}{|c|c|c|c|c|c|c|c|c|c|c|c|}
\hline \multicolumn{12}{|c|}{ South } \\
\hline & ESI & GDP & VCR & SSER & GVA & $\mathrm{HW}$ & IN & TR & FDIA & UR & LUR \\
\hline 4 & 0.01 & 0.08 & 0.01 & $\begin{array}{c}-0.01 \\
\end{array}$ & 0.07 & 0.05 & 0.03 & 0.03 & 0.002 & -0.04 & 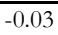 \\
\hline 8 & 0.02 & 0.11 & 0.03 & -0.01 & 0.10 & 0.06 & 0.06 & 0.04 & 0.001 & -0.04 & -0.04 \\
\hline 12 & 0.02 & 0.11 & 0.03 & -0.01 & 0.10 & 0.06 & 0.06 & 0.04 & -0.002 & -0.03 & -0.03 \\
\hline 24 & 0.01 & 0.05 & 0.01 & -0.01 & 0.05 & 0.02 & 0.03 & 0.02 & -0.004 & -0.01 & -0.01 \\
\hline \multicolumn{12}{|c|}{ North } \\
\hline & ESI & GDP & VCR & SSER & GVA & HW & IN & TR & FDIA & UR & LUR \\
\hline 4 & 0.02 & 0.11 & 0.03 & 0.07 & 0.05 & 0.12 & 0.03 & 0.02 & -0.001 & -0.04 & -0.05 \\
\hline 8 & 0.02 & 0.11 & 0.03 & 0.09 & 0.07 & 0.13 & 0.06 & 0.02 & -0.012 & -0.05 & -0.06 \\
\hline 12 & 0.01 & 0.05 & 0.01 & 0.07 & 0.06 & 0.09 & 0.06 & 0.01 & -0.021 & -0.05 & -0.05 \\
\hline 24 & 0.00 & 0.00 & 0.00 & 0.02 & 0.03 & 0.01 & 0.03 & 0.00 & -0.025 & -0.02 & -0.02 \\
\hline
\end{tabular}

Note: ESI = Firm start-up Index; GDP = gross domestic product; VCR = Legality condition Index; SSER = Secondary School Enrolment Rate; GVA = gross value added; HW = Total Hours Worked; IN = Total Investment; TR = Total Remuneration; FDIA $=$ Foreign Direct Investment Attraction Index; UR = Unemployment Rate; LUR = Long-term Unemployment Rate.

Our analysis now concentrates on the forecast error variance decomposition. The main strength of this type of analysis is its ability to capture the weight of different variable innovations on a given variable forecast error variance decomposition. In 
other words, it yields information on the percentage of variation in the forecast error of a variable explained by its own innovation and the proportion explained by innovations in other variables at different horizons.

Table 4 depicts the forecast error variance decomposition of the variables included in the FAVAR models estimated above, and up to a six-year horizon.

The table gives useful information on the relative ability of $A L M P$ to affect employment dynamics at different horizons. According to the variance decomposition at short horizons, ALMP innovations do not play a major role in the quarterly fluctuations of the employment rate. The dynamics of employment are largely dominated by its own shocks, and they indicate that short-run fluctuations in the employment rate display no association with active labour market programmes or with the dynamics of participation rate. For long horizons, we find that both ALMP and participation rate have a certain influence in determining employment dynamics. This influence varies across regions. In fact, while in southern regions, only $7 \%$ of the employment movements are driven by ALMP shocks, in northern regions this percentage doubles (almost 16\%).

Table 4: FEVD of Forecast-error Variance Decomposition

\begin{tabular}{|c|c|c|c|c|c|c|c|}
\hline \multicolumn{8}{|c|}{ South } \\
\hline & 1st PC & 2nd $P C$ & 3th $P C$ & 4th $P C$ & E & Part & ALMP \\
\hline \multicolumn{8}{|c|}{ Employment } \\
\hline 4 & 0.04 & 0.80 & 0.07 & 1.68 & 94.39 & 0.52 & 2.49 \\
\hline 8 & 7.09 & 1.68 & 0.11 & 3.56 & 78.60 & 1.92 & 7.04 \\
\hline 12 & 15.38 & 1.76 & 0.15 & 3.86 & 69.83 & 2.09 & 6.94 \\
\hline 24 & 18.93 & 1.76 & 0.17 & 3.84 & 66.31 & 2.09 & 6.90 \\
\hline \multicolumn{8}{|c|}{ Participation } \\
\hline 4 & 0.02 & 0.14 & 0.17 & 3.01 & 43.22 & 52.27 & 1.18 \\
\hline 8 & 0.02 & 0.14 & 0.22 & 3.90 & 42.24 & 50.66 & 2.83 \\
\hline 12 & 0.12 & 0.14 & 0.23 & 4.22 & 41.74 & 49.95 & 3.60 \\
\hline 24 & 1.13 & 0.17 & 0.28 & 4.33 & 41.11 & 49.04 & 3.93 \\
\hline \multicolumn{8}{|c|}{$A L M P$} \\
\hline 4 & 0.47 & 0.28 & 0.50 & 1.20 & 1.94 & 0.21 & 95.41 \\
\hline 8 & 2.48 & 0.64 & 0.79 & 1.53 & 1.44 & 0.43 & 92.70 \\
\hline 12 & 3.92 & 1.14 & 1.04 & 1.49 & 1.41 & 0.51 & 90.50 \\
\hline 24 & 4.08 & 1.28 & 1.12 & 1.48 & 1.40 & 0.53 & 90.10 \\
\hline \multicolumn{8}{|c|}{ North } \\
\hline & 1 st PC & 2nd PC & 3 th $P C$ & 4th $P C$ & E & Part & $A L M P$ \\
\hline \multicolumn{8}{|c|}{ Employment } \\
\hline 4 & 0.07 & 0.38 & 0.06 & 9.57 & 84.99 & 0.54 & 4.38 \\
\hline 8 & 0.21 & 0.32 & 0.13 & 13.49 & 73.53 & 0.55 & 11.78 \\
\hline 12 & 0.67 & 0.46 & 0.21 & 15.35 & 66.59 & 1.49 & 15.23 \\
\hline 24 & 1.22 & 1.08 & 0.36 & 19.00 & 58.57 & 3.98 & 15.79 \\
\hline \multicolumn{8}{|c|}{ Participation } \\
\hline 4 & 0.42 & 0.39 & 0.68 & 6.91 & 57.54 & 29.74 & 4.32 \\
\hline 8 & 0.42 & 0.33 & 0.57 & 12.58 & 49.48 & 25.40 & 11.22 \\
\hline 12 & 0.53 & 0.50 & 0.51 & 15.36 & 45.01 & 23.95 & 14.14 \\
\hline 24 & 0.77 & 1.48 & 0.45 & 19.62 & 40.10 & 22.98 & 14.61 \\
\hline \multicolumn{8}{|c|}{$A L M P$} \\
\hline 4 & 1.16 & 0.85 & 0.05 & 0.25 & 0.06 & 7.22 & 90.42 \\
\hline 8 & 3.03 & 1.21 & 0.23 & 0.49 & 0.05 & 16.33 & 78.66 \\
\hline 12 & 3.95 & 1.68 & 0.50 & 0.53 & 0.12 & 21.34 & 71.89 \\
\hline 24 & 4.15 & 1.90 & 0.91 & 0.58 & 0.34 & 23.71 & 68.41 \\
\hline
\end{tabular}


Table 4 also illustrates the percentage of variance explained by the estimated common factors. In the South, the first estimated component, which is related to the social end economic context, does significantly affect movements in the employment rate: after six years, it explains almost $19 \%$ of the employment change.

In the northern regions, by contrast, employment dynamics seems to be partially explained by the dynamics of the fourth principal components (related to the remuneration): in particular, movements in the fourth PC after six years account for almost $20 \%$ of employment variation.

Table 5: FEVD - Fraction of Employment rate, Participation rate and ALMP explained by selected variables

\begin{tabular}{|c|c|c|c|c|c|c|c|c|c|c|c|}
\hline \multicolumn{12}{|c|}{ South } \\
\hline Employment & $\begin{array}{l}\text { ESI } \\
\end{array}$ & GDP & VCR & $\begin{array}{l}\text { SSER } \\
\end{array}$ & GVA & HW & IN & TR & FDIA & UR & LUR \\
\hline 4 & 0.309 & 0.687 & 1.612 & 0.046 & 0.683 & 0.334 & 0.033 & 0.106 & 0.083 & 31.249 & 21.716 \\
\hline 8 & 0.438 & 1.780 & 1.964 & 0.212 & 1.885 & 0.377 & 0.196 & 0.330 & 0.085 & 29.793 & 20.800 \\
\hline 12 & 0.448 & 2.682 & 1.992 & 0.467 & 2.902 & 0.376 & 0.395 & 0.534 & 0.123 & 28.989 & 20.216 \\
\hline 24 & 0.486 & 3.755 & 1.958 & 1.012 & 4.168 & 0.497 & 0.666 & 0.782 & 0.279 & 28.460 & 19.919 \\
\hline Participation & ESI & GDP & $\mathrm{VCR}$ & SSER & GVA & $\mathrm{HW}$ & IN & $\mathrm{TR}$ & FDIA & UR & LUR \\
\hline 4 & 0.561 & 0.186 & 1.026 & 0.123 & 0.182 & 0.049 & 0.115 & 0.048 & 0.001 & 6.729 & 5.888 \\
\hline 8 & 0.574 & 0.613 & 1.009 & 0.124 & 0.591 & 0.052 & 0.208 & 0.048 & 0.002 & 6.630 & 5.912 \\
\hline 12 & 0.571 & 0.958 & 1.026 & 0.153 & 0.935 & 0.072 & 0.217 & 0.058 & 0.005 & 6.576 & 5.923 \\
\hline 24 & 0.629 & 1.347 & 1.053 & 0.271 & 1.358 & 0.142 & 0.222 & 0.089 & 0.029 & 6.541 & 5.935 \\
\hline ALMP & ESI & GDP & $\mathrm{VCR}$ & SSER & GVA & $\mathrm{HW}$ & IN & $\mathrm{TR}$ & FDIA & UR & LUR \\
\hline$\overline{4}$ & 1.149 & 2.626 & 0.105 & 0.236 & 2.159 & 0.250 & 1.353 & 0.591 & 0.251 & 0.225 & 1.065 \\
\hline 8 & 0.856 & 5.097 & 0.319 & 1.142 & 4.432 & 0.894 & 2.269 & 0.493 & 0.625 & 0.294 & 2.242 \\
\hline 12 & 1.079 & 7.188 & 0.526 & 2.304 & 6.452 & 1.699 & 2.946 & 0.657 & 1.056 & 0.365 & 2.774 \\
\hline 24 & 2.440 & 9.967 & 0.802 & 4.385 & 9.381 & 2.831 & 3.760 & 1.055 & 2.142 & 0.426 & 3.115 \\
\hline \multicolumn{12}{|c|}{ North } \\
\hline Employment & ESI & GDP & VCR & SSER & GVA & HW & IN & TR & FDIA & UR & LUR \\
\hline 4 & 0.015 & 0.484 & 0.025 & 0.225 & 0.503 & 0.064 & 0.188 & 0.085 & 0.032 & 31.605 & 11.887 \\
\hline 8 & 0.031 & 0.614 & 0.074 & 0.387 & 0.644 & 0.095 & 0.990 & 0.188 & 0.042 & 27.711 & 9.998 \\
\hline 12 & 0.082 & 0.762 & 0.128 & 0.437 & 0.802 & 0.455 & 1.990 & 0.235 & 0.044 & 24.599 & 8.929 \\
\hline 24 & 0.231 & 0.966 & 0.216 & 0.446 & 1.036 & 1.523 & 3.273 & 0.227 & 0.056 & 22.283 & 8.019 \\
\hline Participation & ESI & GDP & VCR & SSER & GVA & $\mathrm{HW}$ & IN & $\mathrm{TR}$ & FDIA & UR & LUR \\
\hline 4 & 0.045 & 0.163 & 0.001 & 0.137 & 0.230 & 0.341 & 0.231 & 0.139 & 0.182 & 0.478 & 2.046 \\
\hline 8 & 0.056 & 0.132 & 0.016 & 0.306 & 0.188 & 0.408 & 0.255 & 0.234 & 0.461 & 0.716 & 2.176 \\
\hline 12 & 0.104 & 0.123 & 0.043 & 0.347 & 0.189 & 0.500 & 0.463 & 0.284 & 0.627 & 0.669 & 1.990 \\
\hline 24 & 0.228 & 0.148 & 0.100 & 0.369 & 0.245 & 1.231 & 0.963 & 0.278 & 0.837 & 0.806 & 1.882 \\
\hline ALMP & ESI & GDP & VCR & SSER & GVA & HW & IN & TR & FDIA & UR & LUR \\
\hline 4 & 0.681 & 0.069 & 1.772 & 3.394 & 0.163 & 1.501 & 0.558 & 0.074 & 0.115 & 4.304 & 1.042 \\
\hline 8 & 0.913 & 0.195 & 1.822 & 2.364 & 0.393 & 3.703 & 1.390 & 0.124 & 0.135 & 8.760 & 1.487 \\
\hline 12 & 1.079 & 0.273 & 1.852 & 2.263 & 0.525 & 5.370 & 1.803 & 0.214 & 0.127 & 11.109 & 1.686 \\
\hline 24 & 1.262 & 0.322 & 1.889 & 2.765 & 0.624 & 6.216 & 2.001 & 0.370 & 0.126 & 12.834 & 1.870 \\
\hline
\end{tabular}

Note: ESI = Firm start-up Index; GDP = gross domestic product; VCR = Legality condition Index; SSER = Secondary School Enrolment Rate; GVA = gross value added; HW = Total Hours Worked; IN $=$ Total Investment; TR $=$ Total Remuneration; FDIA $=$ Foreign Direct Investment Attraction Index; UR = Unemployment Rate; LUR = Long-term Unemployment Rate. 
We may conclude that there are different explanations for employment dynamics in the two areas. In the South neither $A L M P$ nor the participation rate seem to account for changes in the employment rate: employment is driven by its own shocks at short horizon and by social and economic context variables at longer horizon. By contrast, in the northern regions, the employment dynamics is significantly explained by remuneration dynamics.

Finally, we report the fraction of employment rate, participation rate and ALMP explained by the eleven selected variables introduced above in table 5 .

In both models, the variable that exerts the largest influence on employment rate is the unemployment rate. Interestingly, while in the South the dynamics of ALMP is significantly driven by GDP and GVA movements (almost 10\%), in the North changes in active labour market policies are explained by changes in the unemployment rate (about 13\%).

\section{Conclusions}

The study has evaluated whether active labour market policies settled at national level generate asymmetric effects when regions have different economic structures. The empirical analysis studied the possible asymmetries that the implementation of ALMP might produce in the labour market performance of active policies participating regions. We first estimated the common factors of employment by principal components. Then, we have simulated the model to measure the dynamic impact of the ALMP on regional labour markets. ALMP appeared to differently influence employment and participation rate and produce a longer-lasting effect in Northern regions. Therefore, our empirical results highlight the importance of considering the regional economic structure when implementing ALMP.

Finally, the forecast error variance decomposition yielded information on how various structural shocks affect the behaviour of each variable at different horizons. We conclude that there are different explanations for labour market dynamics in the two areas. In the South, labour market indicators are largely driven by their own shocks and by shock in the economic structure. By contrast, in the northern regions, the employment and participation dynamics are significantly explained by active labour market programs. 
Overall, our results highlighted that the large disparities among Italian regions mirror a different functioning of regional labour markets (each regions might have a Beveridge curve that differs in terms of position and slope). As a consequence, a "one-size-fits-all" labour market strategy that does not take into account these disparities, produce asymmetric effects on regional economies. 


\section{References}

Altavilla C. e Caroleo F.E. (2006a) Evaluating the Dynamic Effects of Active Labour Policies in Italy, Labour, 20 (2), 349-382.

Altavilla C. e Caroleo F.E. (2006b) Evaluating Asymmetries in Active Labour Policies: The Case of Italy, in F. E. Caroleo and S. Destefanis (eds) The European Labour Market: Regional Dimensions, Physica Verlag, Heidelberg.

Amendola A., Caroleo F.E. and Garofalo M. (1997) Labour market and Decentralized Decision-making: An Institutional Approach, Labour, 3, 1997.

Bai J. and Ng S. (2002) Determining the Number of Factors in Approximate Factor Models, Econometrica, vol. 70, pp. 191-222

Bernanke, B. S., Boivin J., and Eliasz P. S. (2005) Measuring the Effects of Monetary Policy: A Factor-augmented Vector Autoregressive (FAVAR) Approach, Quarterly Journal of Economics, Vol. 120, No. 1, pp. 387-422.

Bowden, R.( 1980) On the existence and secular stability of the uv loci. Economica No. 47 , pp. 35-50.

Büttner, T. and Prey, H. (1998) Does Active Labour-Market Policy Affect Structural Unemployment? An Empirical Investigation for West German Regions, 1986-1993, Zeitschrift für Wirtschafts- und Sozialwissenschaften, 118, pp. 389-413.

Caliendo M., Hujer R. and Thomsen S.L. (2008) Identifying effect heterogeneity to improve the efficiency of job creation schemes in Germany, Applied Economics, 40:9, pp. 1101-1122.

Calmfors L. (1994) Active Labour Market Policy and Unemployment - a Framework for the analysis of crucial design features OECD Economic Studies, n. 22.

Calmfors L., Forslund A., Hemstròm M. (2001) Does Active Labour Market Policies Work? Lessons from the Swedish Experiences, Swedish Economic Policy Review, vol. 8, n.2, pp 61-124.

Caroleo F.E. and Destefanis S. (2006) The European Labour Market. Regional Dimensions, Physica-Verlag, Heidelberg.

Destefanis S., Fonseca R. (2007) Matching Efficiency and Labour Market Reform in Italy: A Macroeconometric Assessment, Labour, vol. 21(1), pp 57-84.

Dow, J. and L. Dicks Mireaux (1958) The excess demand for labour. a study of conditions in Great Britain, 1946-56, Oxford Economic Papers No. 10, pp. 1-33. 
Eurostat, (2006) Labour market policy database Methodology. Revision of June 2006, Luxembourg, 2006.

Fahr R. and Uwe Sunde (2006) Regional dependencies in job creation: an efficiency analysis for Western Germany, Applied Economics, vol. 38(10), pages 11931206.

Fertig, M., Schmidt C. M. and Schneiderc H. (2006) Active Labor Market Policy in Germany - Is there a Successful Policy Strategy?, Regional Science and Urban Economics, 36, pp. 399-430.

Hagen, T. (2003) Three Approaches to the Evaluation of Active Labour Market Policy in East Germany Using Regional Data, Discussion Paper 03-27, ZEW.

Hansen, B. (1970) Excess demand, unemployment, vacancies and wages, Quarterly Journal of Economics No. 84, pp. 1-23.

Holt, C. and M. David, (1966) The concept of vacancies in a dynamic theory of the labor market, in Measurement and Interpretation of Job Vacancies, ed. NBER. New York: Columbia University Press.

Hujer R., Blien U., Caliendo M., Ziess C. (2002) Macroeconometric Evaluation of Active Labour Market Policies in Germany - A Dynamic Panel Approach Using Regional Data, IZA - Discussion Paper No.616

Hujer R. and Caliendo M. (2000) Evaluation of Active Labour Market Policy: Methodological Concepts and Empirical Estimates, IZA Discussion Paper, n. 236.

Hujer R., Rodrigues P. J. M. and Wolf K. (2007) Estimating the Macroeconomic Effects of Active Labour Market Policies Using Spatial Econometric Methods Eale conference, Oslo.

Hujer, R. and Zeiss, C. (2003) Macroeconomic Impacts of ALMP on the Matching Process in West Germany, Working Paper, J.W.Goethe-University, Frankfurt. Ibourk, A., B. Maillard, S. Perelman, and Sneessens H.R. (2004): “Aggregate Matching Efficiency: A Stochastic Production Frontier Approach, France 1990-1994," Empirica, 31, 1-25.

Ilmakunnas, P., and Pesola H. (2003) Regional Labour Market Matching Functions and Efficiency Analysis, Labour, 17(3), 413-437.

Jackman, R., Layard, R. and Savouri, S. (1990) Mismatch: a framework for thought. CEP discussion paper N.01 
Kluve J., D. Card, M. Fertig, M. Gora, L. Jacobi, P. Jensen, R. Leetmaa, L. Nima, E. Patacchini, S. Schaffner, C.M. Schmidt, B. van der Klaauw , A. Weber (2006) Active Labor Market Policy in Europe: Performance and Perspectives, Springer, erscheint in Kürze.

Kluve, J. (2006) The Effectiveness of European Active Labor Market Policy, IZA Discussion Paper No. 2018

Maré D.C. (2004) Indirect Effects of Active Labour Market Policies, Motu Working Paper 05-01, October.

Martin J.P., Grubb D. (2001) What Works and for Whom: A Review of OECD Countries' Experiences with Active Labour Market Policies, Swedish Economic Policy Review, vol. 8, n.2, pp. 9-56.

Ministero del Lavoro e della Previdenza Sociale (2006) Aggiomamento del quadro informativo sulle politiche del lavoro, Roma.

Ministero del Lavoro e della Previdenza Sociale (2007) Rapporto di monitoraggio delle politiche occupazionali e del lavoro, Roma.

Mortensen, Dale T., (1970) A Theory of Wage and Employment Dynamics, in Edmund S. Phelps (ed.), Microeconomic Foundations of Employment and Inflation Theory, W.W. Norton, New York.

Mortensen D. and Pissarides C. (1994) Job Creation and Job Destruction in the Theory of Unemployment, Review of Economic Studies. 61: 397- 415.

Mourre, G. (2006) Did the pattern of aggregate employment growth change in the euro area in the late 1990s?, Applied Economics, 38:15, pp.1783-1807

Nickell S. and Layard R. (1997) Labour Market Institutions and Economic Performance in Ashenfelter O., Card D., Handbook of Labor Economics, North Holland, London.

Pesaran, H.M. and Smith R. (1995) Estimating Long-Run Relationships from Dynamic Heterogeneous Panels, Journal of Econometrics, 109, pp.79-113.

Petrongolo, B. and Pissarides, C. (2001) Looking into the black box: a survey of the matching function. Journal of Economic Literature 39, 390-431.

Pissarides, C. (1986) Unemployment and vacancies in Britain. Economic Policy 1, 499 559.

Pissarides, C. (2000) Equilibrium Unemployment Theory, 2nd edn. Cambridge, MA: MIT Press. 
Puhani, P. A. (2003) Active Labour Market Policy and Labour Market Flows Evidence from Polish Regional Data, International Journal of Manpower, 24, pp. 897-915.

Shimer, R. (2005) The Cyclical Behavior of Equilibrium Unemployment, Vacancies, and Wages: Evidence and Theory, American Economic Review 95 (1), 25-49.

Stock, J. H. and Watson M. W. (2002) Macroeconomic Forecasting Using Diffusion Indexes, Journal of Business and Economic Statistics, Vol. 20, No. 2, pp. 147-162.

Stock, J. H. and Watson M. W. (1998) Diffusion Indexes, NBER working paper. No. 6702.

Yashiv, E. (2006) The Beveridge Curve, IZA Discussion Paper No. 2479

Yashiv, E. (2006) Labor Search and matching in macroeconomics. European Economic Review, forthcoming.

Warren, R. S. (1991) The Estimation of Frictional Unemployment: A Stochastic Frontier Approach, Review of Economics and Statistics, 73(2), 373-377. 


\section{Appendix 1: Variables used in the empirical analysis}

Transformation Code: 1 - no transformation; 2 - first difference; 3 - logarithm; 4 first difference of logarithm; Sample: 1995-2007; Frequency: A - Annual; Q Quarterly; VI: Average of the Variation Index over the period 1995-2007.

Table A.1: Variables used in factor analysis

\begin{tabular}{|c|c|c|c|c|c|c|c|}
\hline & $\begin{array}{l}\text { Short } \\
\text { name }\end{array}$ & Description & Freq & Tran & $\mathrm{F} / \mathrm{S}$ & VI & Source \\
\hline \multicolumn{8}{|c|}{ Social and economic context } \\
\hline 1 & PCF & Percentage of Cooperative Firms & A & 1 & $\mathrm{~S}$ & 97.9 & Istat \\
\hline 2 & ESI & Firm start-up Index & A & 4 & $\mathrm{~S}$ & 106.6 & Istat \\
\hline 3 & FBR & Firm Birth Rate & A & 1 & $\mathrm{~S}$ & 91.9 & Istat \\
\hline 4 & HIAI & Household Internet Access Index & A & 4 & $\mathrm{~S}$ & 119.1 & Istat \\
\hline 5 & SURP & $\begin{array}{l}\text { Solid urban waste recycled of total solid urban } \\
\text { waste }(\%)\end{array}$ & A & 1 & $\mathrm{~S}$ & 108.8 & Istat \\
\hline 6 & CAPI & $\begin{array}{l}\text { Index of Cultural Activity Participation (number of } \\
\text { visitors per institution) }\end{array}$ & $\mathrm{A}$ & 4 & $\mathrm{~S}$ & 103.4 & Istat \\
\hline 7 & CAPI2 & $\begin{array}{l}\text { Index of Cultural Activity Participation (number of } \\
\text { visitors per Km2) }\end{array}$ & $\mathrm{A}$ & 4 & $\mathrm{~S}$ & 103.0 & Istat \\
\hline 8 & RDP & $\begin{array}{l}\text { Research and Development worker per } 1000 \\
\text { inhabitants }\end{array}$ & A & 1 & $\mathrm{~S}$ & 99.4 & Istat \\
\hline 9 & NV & Number of volunteers (\%) & A & 1 & $\mathrm{~S}$ & 99.2 & Istat \\
\hline 10 & TA & Tourism Intensity Index & A & 4 & $\mathrm{~S}$ & 99.8 & Istat \\
\hline 11 & $\mathrm{ADR}$ & Age Dependency ratio & A & 4 & $\mathrm{~S}$ & 99.7 & Istat \\
\hline 12 & ER & Elderly Ratio & A & 4 & $\mathrm{~S}$ & 112.0 & Istat \\
\hline 13 & $\mathrm{RP}$ & Number of Resident Permits & A & 4 & $\mathrm{~S}$ & 101.2 & Istat \\
\hline 14 & $\mathrm{RF}$ & Number of Foreigners Resident & A & 4 & $\mathrm{~S}$ & 111.3 & Istat \\
\hline 15 & GRA & Growth Rate in Agrculture & A & 1 & $\mathrm{~S}$ & 97.4 & Istat \\
\hline 16 & $\mathrm{HE}$ & Household Expenditure (Levels - 1995m Euro) & A & 4 & $\mathrm{~S}$ & 101.6 & CambridgeReg \\
\hline 17 & VAT & Value added Tax & A & 4 & $\mathrm{~S}$ & 101.3 & Svimez \\
\hline 18 & GDP & GDP (Levels - 1995m Euro) & A & 4 & $\mathrm{~S}$ & 101.1 & CambridgeReg \\
\hline
\end{tabular}

\section{Crime}

\begin{tabular}{llllllll}
19 & RPCI & Recorded Property Crime Index & A & 4 & S & 101.7 & Istat \\
20 & RVCI & Recorded Violent Crime Index & A & 4 & S & 105.6 & Istat \\
21 & CPPI & Crime Public Perception Index & A & 4 & S & 99.1 & Istat \\
$\mathbf{2 2}$ & VCR & Legality condition Index & A & 4 & S & 105.6 & Istat \\
\hline
\end{tabular}

\section{Infrastructure}




\begin{tabular}{cclccccc}
24 & FTTW & Freight-Truck Transportation Weight & A & 4 & S & 102.2 & Istat \\
$\mathbf{2 5}$ & FTTI & Freight-Truck Transportation Index & A & 4 & S & 102.7 & Istat \\
$\mathbf{2 6}$ & RCI & Rail Commuters Index & A & 4 & S & 99.6 & Istat \\
$\mathbf{2 7}$ & PTC & Public transport Commuters (\%) & A & 1 & S & 98.8 & Istat \\
\hline
\end{tabular}

\section{Households and education}

\begin{tabular}{|c|c|c|c|c|c|c|c|}
\hline 28 & SSER & Secondary School Enrollment Rate & A & 1 & S & 98.1 & Istat \\
\hline 29 & SLSP & $\begin{array}{l}\text { School-leavers at second year of secondary school } \\
\text { of total secondary schools }(\%)\end{array}$ & A & 1 & S & 105.0 & Istat \\
\hline 30 & SLFP & $\begin{array}{l}\text { School-leavers at first year of secondary school of } \\
\text { total secondary schools }(\%)\end{array}$ & A & 1 & S & 102.5 & Istat \\
\hline
\end{tabular}

\begin{tabular}{cclccccc} 
Health & & & & & & & \\
31 & SR & Smoker Rate & A & 1 & S & 101.0 & Istat \\
32 & PCPHE & Public Healthcare Expenses per capita & A & 4 & S & 104.8 & Istat \\
33 & PHE & Public Healthcare Expenses (\%) & A & 1 & S & 103.1 & Istat \\
34 & PCHE & Per capita Healthcare Expenses & A & 4 & S & 106.0 & Istat \\
\hline
\end{tabular}

\section{Gross Value Added}

35 GVA Total GVA (Levels - 1995m euro)

36

GVAA GVA Agriculture, Forestry and Fishing (Levels -

37 GVAEM GVA Energy and Manufacturing (Levels - 1995m GVA Energy and Manufacturing (Levels - 1995m
euro) GVAME $\begin{aligned} & \text { GVA Mining and Energy Supply (Levels - 1995m } \\ & \text { euro) }\end{aligned}$

40

GVAFBT GVA Food, Beverages and Tobacco (Levels $1995 \mathrm{~m}$ euro)

GVATC GVA Textiles and Clothing (Levels - 1995m euro)

GVAFC GVA Fuels, Chemicals, Rubber and Plastic Products (Levels - 1995m euro)

42 GVAE GVA Electronics (Levels - 1995m euro)

43 GVATE GVA Transport Equipment (Levels - 1995m euro)

44 GVAOM GVA Other Manufacturing (Levels - 1995m euro)

45 GVAC GVA Construction (Levels - 1995m euro)

46 GVAMS GVA Market Services (Levels - 1995m euro)

47 GVAWR GVA Wholesale and Retail (Levels - 1995m euro)

48 GVAHR GVA Hotels and Restaurants (Levels - 1995m

euro)

49 GVATC GVA Transport and Communications (Levels -

$\mathbf{5 0}$ GVAFS GVA Financial Services (Levels - 1995m euro)

51 GVAOMS GVA Other Market Services (Levels - 1995m euro) A $\quad 4 \quad$ S 102.9 CambridgeReg

52 GVANMS GVA Non-Market Services (Levels-1995m euro) $\quad$ A $\quad 4 \quad$ S $\quad 101.7$ CambridgeReg

\section{Hours Worked}




\begin{tabular}{|c|c|c|c|c|c|c|c|}
\hline 53 & HW & $\begin{array}{l}\text { Total Hours Worked (Hours Per Employee Per } \\
\text { Week - Lfs Measure) }\end{array}$ & A & 4 & S & 102.4 & CambridgeReg \\
\hline 54 & HWA & $\begin{array}{l}\text { Total Hours Worked Agriculture, Forestry And } \\
\text { Fishing }\end{array}$ & A & 4 & S & 102.3 & CambridgeReg \\
\hline 55 & HWEM & Total Hours Worked Energy And Manufacturing & A & 4 & S & 100.2 & CambridgeReg \\
\hline 56 & HWME & Total Hours Worked Mining And Energy Supply & A & 4 & S & 101.9 & CambridgeReg \\
\hline 57 & HWFBT & $\begin{array}{l}\text { Total Hours Worked Food, Beverages And } \\
\text { Tobacco }\end{array}$ & A & 4 & $\mathrm{~S}$ & 101.7 & CambridgeReg \\
\hline 58 & HWTC & Total Hours Worked Textiles And Clothing & A & 4 & $\mathrm{~S}$ & 101.8 & CambridgeReg \\
\hline 59 & HWFC & $\begin{array}{l}\text { Total Hours Worked Fuels, Chemicals, Rubber } \\
\text { And Plastic Products }\end{array}$ & A & 4 & $\mathrm{~S}$ & 101.7 & CambridgeReg \\
\hline 60 & HWE & Total Hours Worked Electronics & A & 4 & $\mathrm{~S}$ & 101.7 & CambridgeReg \\
\hline 61 & HWTE & Total Hours Worked Transport Equipment & A & 4 & $\mathrm{~S}$ & 101.7 & CambridgeReg \\
\hline 62 & HWOM & Total Hours Worked Other Manufacturing & A & 4 & $\mathrm{~S}$ & 101.9 & CambridgeReg \\
\hline 63 & HWC & Total Hours Worked Construction & A & 4 & $\mathrm{~S}$ & 101.5 & CambridgeReg \\
\hline 64 & HWMS & Total Hours Worked Market Services & A & 4 & $\mathrm{~S}$ & 102.4 & CambridgeReg \\
\hline 65 & HWWR & Total Hours Worked Wholesale And Retail & A & 4 & $\mathrm{~S}$ & 101.7 & CambridgeReg \\
\hline 66 & HWHR & Total Hours Worked Hotels And Restaurants & A & 4 & $\mathrm{~S}$ & 101.7 & CambridgeReg \\
\hline 67 & HWTC & $\begin{array}{l}\text { Total Hours Worked Transport And } \\
\text { Communications }\end{array}$ & A & 4 & $\mathrm{~S}$ & 101.7 & CambridgeReg \\
\hline 68 & HWFS & Total Hours Worked Financial Services & A & 4 & $\mathrm{~S}$ & 101.7 & CambridgeReg \\
\hline 69 & HWOMS & Total Hours Worked Other Market Services & A & 4 & $\mathrm{~S}$ & 101.7 & CambridgeReg \\
\hline 70 & HWNMS & Total Hours Worked Non-Market Services & A & 4 & $\mathrm{~S}$ & 101.5 & CambridgeReg \\
\hline
\end{tabular}

\section{Investment}

\begin{tabular}{lclccccc}
$\mathbf{7 1}$ & IN & Total Investment (Levels - 1995m Euro) & A & 4 & S & 101.6 & CambridgeReg \\
$\mathbf{7 2}$ & INA & Total Investment Agriculture, Forestry And & A & 4 & S & 101.7 & CambridgeReg \\
$\mathbf{7 3}$ & INAEM & Total Investment Energy And Manufacturing & A & 4 & S & 100.7 & CambridgeReg \\
$\mathbf{7 4}$ & INME & Total Investment Mining And Energy Supply & A & 4 & S & 99.5 & CambridgeReg \\
$\mathbf{7 5}$ & INFB & Total Investment Food, Beverages And Tobacco & A & 4 & S & 104.0 & CambridgeReg \\
$\mathbf{7 6}$ & INTC & Total Investment Textiles And Clothing & A & 4 & S & 99.9 & CambridgeReg \\
& & Total Investment Fuels, Chemicals, Rubber And & A & 4 & S & 100.4 & CambridgeReg \\
$\mathbf{7 7}$ & INFC & Plastic Products & A & 4 & S & 101.5 & CambridgeReg \\
$\mathbf{7 8}$ & INE & Total Investment Electronics & A & 4 & S & 102.2 & CambridgeReg \\
$\mathbf{7 9}$ & INTE & Total Investment Transport Equipment & A & 4 & S & 100.1 & CambridgeReg \\
$\mathbf{8 0}$ & INOM & Total Investment Other Manufacturing & A & 4 & S & 105.2 & CambridgeReg \\
$\mathbf{8 1}$ & INC & Total Investment Construction & A & 4 & S & 101.6 & CambridgeReg \\
$\mathbf{8 2}$ & INMS & Total Investment Market Services & A & 4 & S & 104.5 & CambridgeReg \\
$\mathbf{8 3}$ & INWR & Total Investment Wholesale And Retail & A & 4 & S & 103.0 & CambridgeReg \\
$\mathbf{8 4}$ & INHR & Total Investment Hotels And Restaurants & A & 4 & S & 103.6 & CambridgeReg \\
$\mathbf{8 5}$ & INTC & Total Investment Transport And Communications & A & 4 & S & 97.7 & CambridgeReg \\
$\mathbf{8 6}$ & INFS & Total Investment Financial Services & A & 4 & S & 100.4 & CambridgeReg \\
$\mathbf{8 7}$ & INOMS & Total Investment Other Market Services & A & 4 & S & 102.5 & CambridgeReg \\
$\mathbf{8 8}$ & INNMS & Total Investment Non-Market Services & & & & \\
\hline
\end{tabular}

\section{Remuneration}

89 TR Total Remuneration (Levels-M Euro) $\quad$ A $\quad 4 \quad$ S $104.1 \quad$ CambridgeReg 


\begin{tabular}{cclccccc}
$\mathbf{9 0}$ & TRA & Total Remuneration Agriculture, Forestry And & A & 4 & S & 102.0 & CambridgeReg \\
$\mathbf{9 1}$ & TREM & Total Remuneration Energy And Manufacturing & A & 4 & S & 102.9 & CambridgeReg \\
$\mathbf{9 2}$ & TRME & Total Remuneration Mining And Energy Supply & A & 4 & S & 102.4 & CambridgeReg \\
$\mathbf{9 3}$ & TRFB & $\begin{array}{l}\text { Total Remuneration Food, Beverages And } \\
\text { Tobacco }\end{array}$ & A & 4 & S & 103.6 & CambridgeReg \\
$\mathbf{9 4}$ & TRTC & Total Remuneration Textiles And Clothing & A & 4 & S & 103.0 & CambridgeReg \\
$\mathbf{9 5}$ & TRFC & Total Remuneration Fuels, Chemicals, Rubber And & A & 4 & S & 103.1 & CambridgeReg \\
$\mathbf{9 6}$ & TRE & Total Remuneration Electronics & A & 4 & S & 103.0 & CambridgeReg \\
$\mathbf{9 7}$ & TRTE & Total Remuneration Transport Equipment & A & 4 & S & 102.5 & CambridgeReg \\
$\mathbf{9 8}$ & TROM & Total Remuneration Other Manufacturing & A & 4 & S & 102.9 & CambridgeReg \\
$\mathbf{9 9}$ & TRC & Total Remuneration Construction & A & 4 & S & 103.2 & CambridgeReg \\
$\mathbf{1 0 0}$ & TRMS & Total Remuneration Market Services & A & 4 & S & 104.9 & CambridgeReg \\
$\mathbf{1 0 1}$ & TRWR & Total Remuneration Wholesale And Retail & A & 4 & S & 104.8 & CambridgeReg \\
$\mathbf{1 0 2}$ & TRHR & Total Remuneration Hotels And Restaurants & A & 4 & S & 104.9 & CambridgeReg \\
$\mathbf{1 0 3}$ & TRTC & Total Remuneration Transport And & A & 4 & S & 103.5 & CambridgeReg \\
$\mathbf{1 0 4}$ & TRFS & Total Remuneration Financial Services & A & 4 & S & 103.2 & CambridgeReg \\
$\mathbf{1 0 5}$ & TROMS & Total Remuneration Other Market Services & A & 4 & S & 107.6 & CambridgeReg \\
$\mathbf{1 0 6}$ & TRNMS & Total Remuneration Non-Market Services & A & 4 & S & 104.7 & CambridgeReg \\
\hline
\end{tabular}

\begin{tabular}{crlccccc}
$\begin{array}{c}\text { Import/Export } \\
107\end{array}$ & FDIA & Foreign Direct Investment Attraction Index & A & 4 & S & 141.0 & Istat \\
108 & EHPC & $\begin{array}{l}\text { Export of high/increasing productivity products } \\
\text { (\% of total export) }\end{array}$ & A & 1 & S & 100.6 & Istat \\
109 & IEE & Intra-EU Exports & Q & 4 & S & 104.9 & ISTAT \\
110 & EEE & Extra-EU Exports & Q & 4 & S & 104.8 & ISTAT \\
\hline
\end{tabular}

\begin{tabular}{cclccccc} 
Fianncial Market & & & & & & \\
111 & CTC & Ratio of Credit to Total Credit & Q & 1 & F & 102.5 & Bank of Italy \\
112 & DTC & Ratio of Deposits to Total Credit & Q & 1 & F & 102.9 & Bank of Italy \\
113 & UCTC & Ratio of Unpaid Credit to Total Credit & Q & 1 & F & 103.2 & Bank of Italy \\
114 & NB & $\begin{array}{l}\text { Ratio of Number of banks to Working-age } \\
\text { Population }\end{array}$ & Q & 1 & S & 104.9 & Bank of Italy \\
115 & GC & Ratio of Granted Credit to Total Credit & Q & 1 & F & 103.0 & Bank of Italy \\
116 & CCTC & Ratio of Claimed Credit to Total Credit & Q & 1 & F & 102.5 & Bank of Italy \\
117 & IL & Interest rate on Loans & Q & 1 & F & 102.9 & Bank of Italy \\
118 & ID & Interest rate on Deposits & Q & 1 & F & 103.2 & Bank of Italy \\
119 & FI & Financial Intermediation Index & A & 4 & S & 104.7 & SVIMEZ \\
\hline
\end{tabular}

\begin{tabular}{cclccccc}
\multicolumn{2}{l}{ Labour Market } & & & & & & \\
120 & UR & Unemployment Rate & Q & 1 & S & 100.8 & ISTAT \\
121 & LUR & Long-term Unemployment Rate & Q & 1 & S & 102.8 & ISTAT \\
122 & LF & Labour force & Q & 4 & S & 103.8 & ISTAT \\
123 & ER & Employment Rate & Q & 1 & S & 100.8 & ISTAT \\
124 & PR & Participation Rate & Q & 1 & S & 121.2 & ISTAT \\
\hline
\end{tabular}




\section{Appendix 2: ALMP}

ALMP are policy interventions targeted at certain sub-groups on the labour market. There exists a large number of various discretionary measures of employment promotion in Italy. According to the statistical classification employed by Eurostat, three different type of intervention can be distinguished: Services, Measures and Supports ${ }^{16}$. The following table summarised the programs we take into account in the empirical part of the paper. As shown in the table we do not consider neither Services nor Support. We concentrate our analysis on Measures.

Table A.2: Active Labour Market Policies considered in the analysis

\section{Classification of interventions by type of action}

\section{Measures}

2 Training

2.2 Workplace training

2.4 Special support for apprenticeship

4 Employment incentives

4.1 Recruitment incentives

4.1.1 Permanent

4.1.2 Temporary

4.2 Employment maintenance incentives

- Regional financial support

5 Supported employment and rehabilitation

5.1 Supported employment

5.2 Rehabilitation

6 Direct job creation

7 Start-up incentives

\section{Other}

Late-retirement incentives

$\underline{\text { Social security decontribution on variable wage }}$

${ }^{16}$ See Eurostat (2006) for a detailed description of the classification used by Eurostat. 